\title{
Coupling groundwater age tracers (CFCs) and in-stream solute time series (DSi) to decipher the reactivity of crystalline watersheds
}

JEAN MARÇAIS ${ }^{1}$, JEAN-RAYNALD DE DREUZY ${ }^{2}$, LUC AQUILINA ${ }^{3}$, LUCA GUILLAUMOT ${ }^{4}$, THIERRY LABASQUE $^{5}$, GILLES PINAY ${ }^{2}$ AND LOUIS A DERRY ${ }^{6}$

${ }^{1}$ INRAe

${ }^{2} \mathrm{CNRS}$

${ }^{3}$ Université de Rennes 1 Géosciences Rennes UMR 6118

${ }^{4}$ International Institute for Applied Systems Analysis(IIASA)

${ }^{5}$ Univ. Rennes, CNRS, UMS 3343

${ }^{6}$ Institut de Physique du Globe de Paris

Presenting Author: jean.marcais@inrae.fr

If weathered-derived solutes time series can characterize the exported weathering flux $[\mathrm{kg} / \mathrm{ha} / \mathrm{yr}]$ of a given catchment, these time series alone are uninformative to characterize the weathering reactivity of a given landscape, ie its weathering dynamic, leading to a given water quality in streamwater. Similarly, weathering rates derived from batch reactors are difficult to upscale to estimate the weathering reactivity at the field scale (White and Brantley, 2003). For these reasons, we propose here to develop a model-based coupling between intermediate age tracers (ages representative of circa 10 to 100 years) with long and in stream dissolved silica time series (15 yrs long) to characterize the weathering enrichment rate (in $\mathrm{mMol} / \mathrm{yr}$ ) water in different Brittany catchments.

We developed a quasi-2D hillslope model that represents the partitioning between stratified groundwater flows and fast flows arising close to the surface seasonally, when the aquifer intersects the land surface. Coupled to a Lagrangian particle tracking technique, the model is able to represent the streamwater transit time distributions dynamics at the catchment scale. We then collected CFCs measurements in wells, springs and streams to characterize the mean transit time variability of the different water storages. We calibrate the different water compartments (storage capacity and flux coming from the different storages) with discharge time series and CFCs measurements.

We found that the seasonal dynamic of the transit time distributions is correlated with the DSi observations. By adding a first order kinetic law to represent the apparent weathering activity, we were able to generate numerical DSi concentrations time series and to reproduce the seasonal patterns observed. We found that the weathering rates in shallow Brittany aquifers are circa $0.003 \mathrm{mMol} / \mathrm{yr}$, consistent with previous weathering estimated carried in crystalline aquifers. 